\title{
Chapter 10 \\ Commentary: Swapping Development Rights to Prevent Flood Plain \\ Development in Flanders: A Legal Architecture Perspective
}

\author{
John Sheehan
}

\section{Introduction}

Nature-based solutions for FRM are unavoidably impacted by the particularity of overarching national property laws and, especially, local property ownership and land use patterns. Crabbé and Coppens (this volume) in their paper "Swapping development rights in swampy land: strategic instruments/strategies to prevent flood plain development in Flanders" have chosen to respond to the question of particularity of property laws through the lens of flood plain development in the northern Belgian region of Flanders. In reflecting on the question of particularity in as much as it relates to NBS in FRM, I have also chosen a distinct approach that, however, eschews (without any overt or covert judgement) the empirical approach of Crabbé and Coppens.

This commentary is therefore imbedded with theoretical underpinnings of property rights that are, in any event, arguably and, indeed necessarily, informed by pragmatic legal considerations. To that end, the commentary changes gears but does not dismiss the road map evidenced in the empirical approach adopted in the Flanders case study. There are no broad rules or generalizations for NBS for FRM, and hence any conclusions must be absolutely neutral and objective. Crabbé and Coppens refer to the overall impact of the gewestplannen on land prices, and the resultant difficulties encountered in any changes to planned land uses presumably to address flood risks. Different disciplines necessitate consideration of FRM from a particular standpoint. Crabbé and Coppens appear to come from such a particular standpoint, providing an empirical consideration of FRM through an examination of the various opportunities available for governance of flood planning management through either

\footnotetext{
J. Sheehan $(\varangle)$

Faculty of Social and Economic Studies, Institute for Economic and Environmental Policy (IEEP), J. E. Purkyně University, Ústí nad Labem, Czech Republic e-mail: John.Sheehan@uts.edu.au
}

Faculty of Society and Design, Bond University, Gold Coast, Australia 
market-driven instruments or, alternatively, government-led initiatives; essentially a land use planning discourse.

The issue of selection of the appropriate FRM governance models is, however, not exceptional, yet neither is the process of selection commonly encountered. Perhaps the task of ascertaining NBS for FRM necessitates an unexpected or even unanticipated focus on the process of selection of suitable and efficacious governance models in such specific circumstances. The impact upon private property rights ought not to be underestimated, and hence, from my perspective, the legal architecture surrounding any NBS for FRM is the touchstone for effectivity and efficiency. Whilst not suggesting any disrespect to other disciplines, the legal architecture could be described as the liet motif of any NBS for FRM on private land. Indeed, Crabbé and Coppens recognise this aspect to some degree when they note the reality of the oversupplied Flanders marketplace, which is adversely impacting the utility of possible transferable development rights for FRM. They also note mandatory land adjustment for FRM is similarly infused with the reality of the value of land in the hands of private owners who are unwilling to lose any value through the adjustment process.

Aside from FRM, even globally significant endeavours such as archaeology have also been impacted by the value of private land. For example, the governmentsanctioned excavation in the 1890s by French archaeologists of the ancient Greek sanctuary of Delphi was delayed by some of three hundred dispossessed villagers who argued for better compensation for their private land beneath which lay the (now) UNESCO World Heritage Site (Cline 2017, 178). Unsurprisingly, with private property rights whirling around prospective NBS for FRM, the legal architecture is revealed as paramount.

\section{Legal Architecture}

Crabbé and Coppens determine that NBS for FRM in the face of perhaps significant financial compensation appropriately accruing to holders of private property is the major challenge for municipal, provincial and regional governments in Flanders. However, an understanding of the impact of NBS for FRM upon private property rights must first be nominally grounded in the constitutive conditions-social, legal, and institutional. Then secondly, the specific territorial composition of the conditions will subsequently confer legality and legitimacy upon those remedies considered appropriate to the particular territory. Such a starting point transposes the common narrative of the scientifically-informed foundation of FRM to a very different narrative of territorial politico-legal innovation within the reality of the driver of change, such as climate (Van Straalen et al. 2018, 190). The legal architecture of flood-prone areas in Flanders (and indeed, elsewhere) provides an important necessary impulse for the selection of the appropriate policy (instrument) to achieve the eagerly sought after NBS for FRM. Hence, the selection process is imbedded with the recognition that much flood-prone land is more often than not held as private property rights. I 
would argue that the common analytical distinctions between public environmental law and the law of private property ought not lead to presumptions that the legal architecture is so separate as to be irreconcilable, especially when tasked crucially with identifying a methodology (or methodologies) for FRM.

Indeed, whether the overarching legal architecture is based in a civil code regime such as in Belgium or a common law regime such as in England appears increasingly irrelevant, notably in environmental law. Convergence of intent allied with international law has increasingly overcome lingering conceptual historic obstacles thereby rendering omnibus environmental law recognizable and legitimate (Girard 2016; Needham et al. 2018, 53). Beyond Europe, this increasing irrelevance of legal genealogy is also manifested in the Asian Pacific region where notwithstanding the marked legal and political diversity of regional nation states, Couzens and Stephens detect "a number of common strands in the way in which governments in the region are approaching environmental challenges" (Couzens and Stephens 2017, 1).

Returning to the case study, the constitutive conditions-social, legal, institutional-clearly empower the municipal, provincial and regional governments in Flanders, and yet an overarching politico-legal remedy for NBS for FRM especially on private land appears to be remote. Firstly, why is this so? Secondly, why there are such almost intractable difficulties with implementation of broad-scale NBS for FRM in Flanders (and elsewhere)? From a property rights standpoint, the answer to both questions lies in a failure to appreciate any nature-based solution for FRM on private land is necessarily imbedded with theoretical underpinnings of property rights informed by pragmatic legal considerations. Perhaps, such a response merely reveals how the legal mind approaches the requisite accommodation flagged between FRM and private property rights. Possessive individualism lies at the heart of the theory of private property rights in respect of which Macpherson stated: "human society is essentially a series of market relations" (Macpherson 1962, 270). Nevertheless, Crabbé and Coppens appear uncomfortable with alternatives to government-led initiatives for FRM such as market-driven instruments notably transferable development rights or mandatory land readjustment. Yet, such alternatives represent a suite of tools that, in appropriate circumstances, can respond effectively to the presence of private property rights and address the significant financial worth of such privately held rights. Nonetheless, it is known that alternatives to government-led initiatives cannot serve as panacea for all management needs when flood risk has to be confronted.

Whilst somewhat prosaic, it is important to recognise NBS for FRM necessitate intervening in private property rights, and, ordinarily one can anticipate that to need significantly more land than more traditional flood risk "grey infrastructure" would require. Nevertheless, in a heartening observation Freyfogle stated: "private property, in fact, has been an evolving, organic institution with ownership rights that have varied greatly from era to era and place to place. The vast potential for further change of this institution very much needs exploring" (Freyfogle 2003, 7). 


\section{Research and Practice Questions Arising}

Unsurprisingly, private property rights have always presented a conundrum for liberal-democratic states such as Belgium, Australia, or elsewhere. Freyfogle has further stated, "one has to do with the mismatch between the way private land is portrayed in law and culture and the way it exists in the real world of nature" (Freyfogle 2003, 7). This dual view of land, which includes private property rights, reveals national property law can only be ignored perilously by other disciplines when contemplating such issues as NBS to FRM on private land. The solutions sought after will only be realized through a cross-disciplinary collaboration between the perspectives offered by law and other disciplines where private land is to be the focus of the solution. The Flanders case study reveals existing attempts to introduce NBS for FRM utilizing private land frankly remain inefficient and probably in the main, ineffective. Because the question of particularity of property law impacts so severely on the prospect for efficiency and effectiveness, I consider the Flanders case study clearly reveals a need for urgent collaborative cross-disciplinary research into the theory and practice of flood risk mitigation and adaptation measures, notably where intervention in private property rights is required.

Acknowledgements Open access of this chapter is funded by COST Action No. CA16209 Natural flood retention on private land, LAND4FLOOD (www.land4flood.eu), supported by COST (European Cooperation in Science and Technology).

\section{References}

Cline EH (2017) Three stones make a wall: the history of archaeology. Princeton University Press, Princeton

Couzens E, Stephens T (2017) The prospects for a truly regional Asian Pacific environmental law? Asia Pac J Environ Law 20:1-4

Freyfogle ET (2003) The land we share: private property and the common good. Island Press, Washington DC

Girard F (2016) La propriete inclusive au service des biens environnementaux Repenser la propriete a partir du bundle of rights. Cah Droit, Sci \& Technol 6:185-236

Macpherson CB (1962) The political theory of possessive individualism: Hobbes to Locke. Oxford University Press, Oxford

Needham B, Buitelaar E, Hartmann T (2018) Planning, law and economics, 2nd edn. Routledge, London

Van Straalen FM, Hartmann T, Sheehan J (2018) Conclusion: the social construction of changing environmental conditions. In: van Straalen FM, Hartmann T, Sheehan J (eds) Property rights and climate change: land use under changing environmental conditions. Routledge, London, pp $182-190$ 
Prof. John Sheehan is currently Adjunct Professor in the Faculty of Design Architecture and Building at University of Technology Sydney. He is also Adjunct Professor in the Faculty of Society and Design at Bond University, Gold Coast, Queensland. In 2017, John was appointed Guest Professor with the Institute for Economic and Environmental Policy (IEEP) in the Faculty of Social and Economic Studies at J. E. Purkyne University in Usti nad Labem, Czech Republic. In 2003 he was appointed the independent Chair of the Project Advisory Committee Water Property Titles Program, Land and Water Australia, which was a research project funded by the Commonwealth Government to establish a water titling system for Australia.

Open Access This chapter is licensed under the terms of the Creative Commons Attribution 4.0 International License (http://creativecommons.org/licenses/by/4.0/), which permits use, sharing, adaptation, distribution and reproduction in any medium or format, as long as you give appropriate credit to the original author(s) and the source, provide a link to the Creative Commons license and indicate if changes were made.

The images or other third party material in this chapter are included in the chapter's Creative Commons license, unless indicated otherwise in a credit line to the material. If material is not included in the chapter's Creative Commons license and your intended use is not permitted by statutory regulation or exceeds the permitted use, you will need to obtain permission directly from the copyright holder.

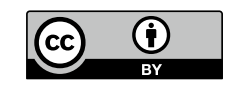

